showed high sensitivity in all age-groups; this is of primary importance since early identification of children with latent tuberculosis infection and appropriate chemoprophylaxis represent the most important tool to reduce tuberculosis burden.

\section{ANTIBIOTIC USE IN INFANTS IN THE FIRST YEAR OF LIFE IN FIVE EUROPEAN COUNTRIES}

doi:10.1136/archdischild-2012-302724.0042

M van Stuijvenberg, J Stam, P Sauer, for the MIPS 1 Study Group. Pediatrics, Beatrix Childrens Hospital UMCG, Groningen, The Netherlands

Background and aims In view of antibiotic resistance problems and development of atopic diseases there is a need to improve the appropriateness of antibiotic use, especially in young children. Antibiotics are mostly prescribed for upper respiratory tract infections (URTI) and otitis media (OM), while these are mostly of viral origin. We report antibiotic use for these infections in otherwise healthy term infants up to one year of age.

Methods The study was part of a multicenter nutritional intervention study (DRKS00000201) in which the parents recorded illness symptoms and antibiotic use of their child in a diary. Logistic regression was used to analyse differences in antibiotic use between the participating countries (Italy, Netherlands, Austria, Switzerland, and Germany).

Results The study was completed by 839 children; 4798 illness episodes were reported, of which 501 (10.4\%, range 3.9-18.4\%) were treated with antibiotics.

URTI occurred in 2855 (59\%) episodes (range 55-64\%). Antibiotics were used more often in Italy compared to Switzerland: $18.8 \%$ versus $1.4 \%, \mathrm{OR}=0.06(\mathrm{CI} 95 \%=0.02-0.1)$.

OM occurred in 184 (3.8\%) episodes (range 2.0-6.8\%). Antibiotics were used more often in Italy compared to the Netherlands: $82 \%$ versus $55 \%, \mathrm{OR}=0.3(\mathrm{CI} 95 \%=0.1-0.6)$.

Conclusions Antibiotic use varies significantly between European countries while the occurrence of URTI and OM is rather similar. In the development of methods to increase appropriate use of antibiotics other factors, such as physicians attitude, parental influence, and other socio-economic determinants may better be taken into account.

\section{EVALUATION OF THE EFFICACY OF L-ISOLEUCINE SUPPLEMENTED FOOD AND VITAMIN D IN THE TREATMENT OF ACUTE DIARRHEA IN CHILDREN}

doi:10.1136/archdischild-2012-302724.0043

NH Alam, H Ashraf. Centre for Nutrition and Food Security (CNFS), International Centre for Diarrhoeal Disease Research, Bangladesh (ICDDR, B), Dhaka, Bangladesh

Introduction Antimicrobial peptides represent an important component of the innate defense of organisms and have activities against all microbes. Recently, L-isoleucine and Vitamin D have been found to induce antimicrobial peptides. Therefore, L-isoleucine and vitamin $\mathrm{D}$ might have therapeutic potentials in the management of infectious diarrhea.

Objectives The objectives of this study were to examine if addition of L-isoleucine and/or vitamin $\mathrm{D}$ to a diet reduces the stool weight and/or duration of acute diarrhea in children.

Methods This was a double blind randomized clinical trial in 107 children aged 6 to 36 months attending the ICDDRB hospital with acute diarrhea: 28 children received:

a. L-isoleucine $(2 \mathrm{~g} / \mathrm{d})$ added to milk suji

b. 27 received Vitamin D 1000 IU/d added to Milk suji;

c. $26 \mathrm{~L}$-isoleucine $(2 \mathrm{~g} / \mathrm{d})$ plus vitamin D $1000 \mathrm{IU} / \mathrm{d}$;

4. 26 Milk suji without L-isoleucine and vitamin $\mathrm{D}$.
Other managements were similar in all groups. Stool weight(g) and duration of diarrhea were the primary outcomes.

Results There was a trend in stool weight reduction in the groups receiving $\mathrm{L}$-isoleucine and the reduction was significant on day 2 (mean $\pm \mathrm{SD}$, L-isoleucine vs. vit $\mathrm{D}$ vs. $\mathrm{L}$-isoleucine + vit $\mathrm{D}$ vs. control, $276 \pm 228$ vs. $386 \pm 302$ vs. $301 \pm 181$ vs. $447 \pm 325, p=0.039)$ and day3 ( $176 \pm 157$ vs. $321 \pm 273$ vs. $276 \pm 169$ vs. $341 \pm 292, p=0.045)$. The duration of diarrhea was similar in all groups.

Conclusion L-isoleucine supplemented food reduces stool weight in children with acute diarrhea.

\section{COMPARISON OF THE EFFICACY OF C-REACTIVE PROTEIN, PROCALCITONIN, INTERLEUKIN-6 LEVELS AND NEW LEUKOCYTE PARAMETERS IN THE DIAGNOSIS OF NEONATAL SEPSIS}

doi:10.1136/archdischild-2012-302724.0044

'T Çelik, ${ }^{2} 0$ Portakal, 'Ş Yiğit, ${ }^{3} \mathrm{G}$ Hasçelik, ${ }^{1} \mathrm{~A}$ Korkmaz, ${ }^{1} \mathrm{M}$ Yurdakök. 'Department of Pediatrics, Division of Neonatology, Hacettepe University, Faculty of Medicine; ${ }^{2}$ Department of Biochemistry; ${ }^{3}$ Department of Microbiology, Hacetepe University, Faculty of Medicine, Ankara, Turkey

Background and aims Sepsis is an important cause of morbidity and mortality among newborn infants. Blood culture is the gold standard. Early and definitive diagnosis of neonatal sepsis is difficult because its sings and symptoms are nonspecific. New leukocyte parameters such as neutrophil volume (MNV), conductivity (MNC), scattering (MNS) and volume distribution width (NDW) were introduced in the diagnosis of sepsis recently. We aimed to investigate these parameters in newborn sepsis and compare their efficacy with serum CRP, Procalcitonin (PCT), IL-6 levels.

Methods This study was conducted in Hacettepe University Neonatology Unit, between July 2010 and February 2012. Total 227 newborns, 116 sepsis (40 proven, 76 clinical sepsis) and 111 control included in the study.

Results Results are summarized in the Table 1.

Abstract 44 Table 1

\begin{tabular}{lcccccc}
\hline & $\begin{array}{c}\text { Cut-off } \\
\text { levels }\end{array}$ & $\begin{array}{c}\text { Sensitivity } \\
(\%)\end{array}$ & $\begin{array}{c}\text { Specificity } \\
(\%)\end{array}$ & PPV (\%) & NPV (\%) & AUC (\%) \\
\hline CRP (mg/dl) & $>0.16$ & 75.0 & 76.3 & 50.8 & 91.9 & 77.7 \\
PCT (ng/dl) & $>0.44$ & 75.0 & 86.0 & 60.4 & 89.3 & 86.9 \\
IL-6 (pg/ml) & $>15.40$ & 70.8 & 74.2 & 45.5 & 91.0 & 72.5 \\
I/T ratio & $>0.19$ & 62.5 & 92.5 & 79.4 & 88.9 & 81.5 \\
MNV (au) & $>159.50$ & 37.5 & 94.6 & 71.4 & 80.8 & 63.4 \\
MNC (au) & $<144.50$ & 78.4 & 46.8 & 35.2 & 86.7 & 62.6 \\
MNS (au) & $<141.50$ & 86.5 & 37.6 & 32.7 & 87.2 & 64.5 \\
NDW (au) & $>29.25$ & 66.7 & 75.3 & 43.9 & 84.0 & 68.2 \\
\hline
\end{tabular}

Sensitivity, specificity, positive and ne

Conclusions In conclusion new CBC parameters can be helpful in differential diagnosis of newborn sepsis in addition to other screening parameters. MNV seems the most useful parameter with the highest spesifity.

\section{EFFECT OF A MULTIMODAL INTERVENTION PROGRAM TO PREVENT OBESITY IN EARLY CHILDHOOD}

doi:10.1136/archdischild-2012-302724.0045

${ }^{1} \mathrm{HM}$ Donkor, 'JH Grundt, 'J Hurum, 'ABK Sundby, ${ }^{2} \mathrm{~T}$ Skundberg, ${ }^{3,4} \mathrm{~T}$ Markestad. ${ }^{1}$ Department of Paediatrics, Innlandet Hospital Trust, Lillehammer Hospital, Lillehammer, ${ }^{2}$ Department of Paediatrics, Innlandet Hospital Trust, Gjövik Hospital, Gjövik; ${ }^{3}$ Research Division, Innlandet Hospital Trust, Brumunddal; " 4 Department of Clinical Medicine, University of Bergen, Bergen, Norway 